\title{
A Diagnosis and Model Suggestion Regarding Bars in Repertoire and Solfege Methods Used in Vocal and Choir Education Programs*
}

\author{
İvan CCELAK ${ }^{* *}$
}

\begin{abstract}
The main aim of the research is to determine whether the rhythm instruction within the scope of solfege education offered in vocal and choir-training programs is sufficient in terms of content and method; to determine if the rhythm patterns in vocal and choir repertoire correspond to rhythm instruction; and to present a model suggestion.

In collecting data for this research, survey method is used and employed in three main titles. Answering the research question, it is concluded that the scope of rhythm instruction and education, of which the presence within solfege education is presumed, is lacking in terms of bar and rhythm patterns. In order to address their adequate overlapping between the instructed bars and those in vocal and choir repertoires, the need for a method addressing these deficiencies and suggestions concerning the content of a proposed method regarding rhythm education are provided.
\end{abstract}

Keywords: Voice, chorus, solfege, measure, rhythm.

\section{SUMMARY}

Purpose and Significance: This study aims to detect whether measure teaching, which is included in solfege training in the fields of art; such as singing and choir training, is satisfying enough or not, and it aspires to confirm whether the measures in the repertoire of singing and choir training overlap with measure teaching.

\footnotetext{
* This article has been produced from the Ph. D dissertation called "The Place of Rhythm Teaching in Solfege Education Included in the Programs of Singing and Choir Education".

${ }^{* *}$ Expert Dr.Ankara University, State Conservatory, Ankara, Turkey.
} 
This study is important due to several following points: it is the first comprehensive study in relation to rhythm in graduate level, it lays bare the differences between the measure teaching given within the scope of solfege course and the expected results, it determines the deficiencies in measure teaching, it leads the measure teaching to become systematic in terms of its content for singing and choir training and to develop more sophisticated and comprehensive plans in constructing programs in relation to duration and comprehension, it provides people preparing and developing solfege programs with important data about measure teaching.

Method: In this research, comparative scanning model is used. The solfege methods used in singing and choir training is defined and data is obtained by analyzing the containing exercises in terms of measure. The data is acquired by analyzing the measures which were defined by the repertoire of singing and choir; and the results are reached by comparing the data. Lastly, this study is finalized by interpreting these results.

Results: The results reached by analyzing the data are divided into three parts:

1. There is only one measure (9/4) taking part in solfege methods, yet it is not included in the repertoire of singing and choir training.

2. In the measures, which are common in both solfege methods and in the repertoire of singing and choir training, there are two measures composed of double and triple units and there are some measures with three and four units. Moreover, these measures are used more than once in limited number of exercises.

3. There are $19(57.57 \%)$ measures not included in the methods but exist in singing and choir repertoire. These measures are composed of the combined / limping $(5 / 8,7 / 8,8 / 8$, etc.) measures in which the double and triple units are used together.

Discussions and Conclusions: This research deals with the rhythm training included in solfege training in singing and choir education. The methodical applicability of the content of this education is explored. It is found out that the rhythm education included in the solfege training is immensely deficient and the measures taught and the ones in singing and choir training do not overlap. 


\title{
Şan ve Koro Eğitimi Programlarında Kullanılan Solfej Metotları ve Repertuarındaki Ölçüler Konusunda Bir Saptama ve Model Önerisi"
}

\author{
İvan ÇELAK ${ }^{* * *}$
}

\begin{abstract}
ÖZ. Araştırmanın temel amacı, şan ve koro Anasanat/Sanat dallarında solfej eğitimi kapsamında yer alan tartım öğretiminin içerik ve metodik açıdan yeterliğini ortaya çıkarmaktır. $\mathrm{Bu}$ amaç doğrultusunda, şan ve koro repertuarındaki ölçülerin, öğretim sırasında öğretilen ölçülerle örtüşüp örtüşmediğini saptamak ve bir model önerisinde bulunmaktır.

$\mathrm{Bu}$ araştırmadaki verilerin toplanmasında, tarama yöntemi kullanılmıştır. Tez probleminin araştırılması sonucunda, solfej eğitimi içinde yer aldığı varsayılan tartım (ritm) eğitimi ve öğretimi boyutunun, ölçü açısından eksik olduğu saptanmıştır. Öğretilen ölçülerin, şan ve koro repertuarındaki ölçülerle yeterli derecede örtüşmemesinden doğan eksiklikleri tamamlamak için, bir solfej metodunun yazılması gerekliliği ve yazılacak bir metodun tartım eğitimi açısından içeriğine ilişkin öneriler sunulmuştur.
\end{abstract}

Anahtar Sözcükler: Şan, Koro, Solfej, Ölçü, Tartım.

\footnotetext{
Bu makale "Şan ve Koro Eğitimi Programlarında Uygulanan Solfej Eğitiminde Tartım Öğretiminin Yeri ve Bir Model Önerisi” adlı doktora tezinden üretilmiştir.

** Uzman Dr. Ankara Üniversitesi, Devlet Konservatuvarı, Ankara, Türkiye.
} 


\section{GíRiş}

Şan ve koro eğitimi programları diğer sanat dalları programları ile karşılaştırıldığında, solfej dersinin bütün programlarda yer aldığı gözlemlenmektedir. Örneğin, bütün sanat dalları programlarında solfej dersi yardımcı-zorunlu ders olarak yer almakla birlikte, her sanat dalı için ayrı ayrı planlanmaktadır. Dolayısıyla, örneğin şan bölümü için solfej dersinin süresi, içeriği ve işleniş̧i, dans bölümündeki süre, içerik ve işlenişe göre, bölümün mesleki amaçlarına ve gereksinimlerine göre farklılıklar gösterecektir.

Solfej eğitiminin belirli bir sanat dalına (çalgı, ses, dans, tiyatro) daha fazla etki yapabilmesi için, ortak solfej eğitiminden daha çok, belirli bir sanat dalına uygun, bir solfej eğitiminin verilmesi gerektiği düşünülebilir. Her bir sanat dalının kendine özgü mesleki eğitimi ve bu eğitimin sonucunun hedeflenen düzeyde olabilmesi için, o dala özgü, solfej eğitiminin ve onun önemli bir boyutunu oluşturan ölçü ve dolayısıyla tartım eğitiminin, içerik ve metodik olarak iyi örgütlenmesi gerekmektedir.

Bütün sanat dallarında olduğu gibi, şan ve koro eğitiminde de, solfej eğitimi sonucunda, öğrencilerin donanımlı olması gerekmektedir. Oysa, eğitim sırasında öğrencilerin şan ve koro parçalarında, belirli ölçü çözümlemelerinde ve özellikle aksak ölçülerde, güçlüklerle karşılaştıkları gözlemlenmektedir. İyi bir donanıma ulaşabilmek, yani bu becerileri yükseltebilmek için, solfej öğretim programlarının, şan ve koro sanat dalları gereksinimlerine göre (şan ve koro repertuarından da hareketle) yapılması, bunun daha sağlıklı yapılabilmesi için de, solfej eğitimi kapsamında yer alan ölçü öğretimini ele almak gerekmektedir.

\section{Araştırmanın Problemi}

$\mathrm{Bu}$ araştırmada, şan ve koro sanat dallarında, solfej eğitimi kapsamında verilen ölçü öğretiminin durumu ele alınmaktadır. Bu eğitimin içeriğinin, şan ve koro sanat dalları için, metodik açıdan uygunluğunun araştırılması gerekmektedir.

Araştırmanın temel problemi şöyle belirlenebilir: Şan ve koro eğitimi veren mesleki öğretim programlarında, uygulanan solfej eğitimi içinde, yer aldığı varsayılan ölçü öğretiminin boyutu hangi düzeydedir? Kapsamı nedir? Okutulan kitaplar, metotlar, yapılan çalışmalar ve eğitim yöntemleri açısından şan ve koro sanat dallarına ve repertuarına uygun mudur? Ve okutulan kitaplar ne derece yeterlidir? 


\section{Alt Problemler}

Durumun (problemin) araştırılmasında:

a) Solfej eğitimi içinde yer aldığı varsayılan ölçü öğretiminin boyutu ne düzeydedir?

b) Şan ve koro sanat dallarında ölçü öğretiminin kapsamı nelerdir?

c) Tartım öğretiminde kullanılan ders kitapları, içerik olarak şan ve koro sanat dalları için yeterli midir?

d)Tartım öğretiminde hangi ölçüler öğretilmektedir? sorularına cevaplar aranacaktır.

\section{Araştırmanın Amacı}

Araştırmanın amacı, şan ve koro sanat dallarında solfej eğitimi kapsamında yer alan, ölçü öğretiminin içerik açıdan yeterli olup olmadığını, şan ve koro repertuarındaki ölçülerin, ölçü öğretimi ile örtüşüp örtüşmediğini saptamaktır. Bu amaç doğrultusunda;

a) Şan ve koro repertuarından incelenecek olan parçaların saptanması,

b) Repertuardaki parçaların ölçü açısından incelenmesi,

c) Solfej ders kitaplarının ölçü açısından şan ve koro repertuarına destek derecesinin saptanmas1,

d) Şan ve koro sanat dalları öğrencilerinin solfej eğitimi süreci içinde aldıkları, ölçü öğretiminin içerik açısından incelenmesi amaçlanmaktadır.

\section{Araştırmanın Önemi}

$\mathrm{Bu}$ araştırma,

a) Şan ve koro repertuarından yola çıkarak, tartımla ilgili lisansüstü düzeyde yapılan kapsamlı ilk çalışma olması açısından,

b) Solfej dersi kapsamında verilen ölçü öğretiminin ve beklenilen sonuç arasındaki farkları ortaya koyması ve ölçü öğretimindeki eksiklileri saptaması açılarından,

c) Şan ve koro sanat dalları için, ölçü öğretiminin içerik açısından sistematik olmasını, programların yapılandırılmasında süre ve kapsam açısından daha sağlıklı planlama yapılmasını olumlu yönlendirmesi açısından,

d) Solfej programı hazırlayan veya geliştiren kişilere, ölçü öğretimi ile ilgili önemli verilerin sağlanması ve yol gösterici bir çalışma olması açısından, 
e) Şan ve koro öğrencilerinin ölçü öğretiminden edinecekleri becerilerin meslek yaşamlarına kolaylık sağlayacak olması açısından önem taşımaktadır.

\section{Araştırmanın Modeli}

\section{YÖNTEM}

$\mathrm{Bu}$ araştırmada, karşılaştırmalı tarama modeli kullanılmıştır.

a) Şan ve koro eğitiminde kullanılan solfej metotları saptanmış, ölçü açısından analiz edilerek, veriler elde edilmiş,

b) Şan ve koro repertuarı saptanmış, ölçüler analiz edilerek veriler ortaya çıkartılmış,

c) Şan ve koro repertuarındaki ve metotlardaki veriler karşılaştırılmış, bulgulara ulaşılmış ve yorumlanarak araştırma sonuçlandırılmıştır.

\section{Evren ve Örneklem}

Araştırma herhangi bir evrene genellenmemiş olup, sadece ilgili örneklemler çerçevesinde yapılmıştır.

a) Araştırmanın yapıldığı A.Ü. Devlet Konservatuvarı Koro Anasanat Dalı ve H.Ü. Ankara Devlet Konservatuvarı Opera Anasanat Dalı programlar1,

b) Belirlenen solfej metotları ve seçilen eserler, kendi alanlarını temsil eder nitelikte bir örneklem oluşturur.

Araştırma için belirlenen solfej metotları, ilgili programların solfej eğitiminde kullanılan temel solfej metotlarının tamamını; seçilen eserler de hem öğrenim sürecinde hem de mezuniyet sonrası mesleki yaşamla karşılaşılan repertuarı temsil edebilecek şan ve koro repertuarı örneklemi şu yöntemle belirlenmiştir:

\section{Şan repertuarı}

Seçilen eserler, genellikle öğrencilerin ölçü açısından karşılaştıkları zorluklar göz önünde tutularak seçilmiştir. Bu eserler sınıflara, bestecilere, eser türlerine ve ses gruplarına göre sınıflandırılmış ve incelenmiştir.

\section{Koro repertuarı}

Aşağıda da görüldüğü gibi repertuardaki eserler öncelikle türlerine göre sınıflandırılmış, her kategoriden seçilen eserler, genellikle öğrencilerin ölçü açısından zorlanacakları varsayılan nitelikteki eserlerden oluşturulmuştur. 
1) Opera eserleri

2) Sahne eserleri

3) Diğer eserler:
a) Madrigal
b) Koral
c) Missa
d) Spiritüel
e) Motet

4) Ulusal eserler:

a) Şark1

b) Türkü

c) Marş

5) Popüler eserler

\section{Verilerin Toplanması}

$\mathrm{Bu}$ araştırmadaki verilerin toplanmasında, müziksel analiz yöntemi kullanılmış ve ilgili solfej metotlarından, ölçülere yönelik veriler toplanmiştır.

Araştırma üç ana başlık altında yapılmıştır:

a) Şan ve koro bölümlerinde solfej eğitiminde kullanılan solfej metotların saptanmasi ve incelenmesi,

b) Koro repertuarını oluşturan eserlerin saptanması ve incelenmesi,

c) Şan repertuarını oluşturan eserlerin saptanması ve incelenmesi.

Solfej eğitiminde okutulan solfej metotlarının saptanmasında, Ankara Üniversitesi Devlet Konservatuvarı Opera-Koro Bölümü, Koro Anasanat Dalı ve Hacettepe Üniversitesi Devlet Konservatuvarı Şan Sanat Dalı için solfej dersi veren öğretim elemanları ile görüşülmüş, görüşme sonucunda aşağıdaki yedi metodun kullanılmakta olduğu saptanmıştır.

Muammer SUN, Solfej 1

Muammer SUN, Solfej 2

Albert LAVIGNAC, Des Solfeges 1 A

Albert LAVIGNAC, Des Solfeges 2 A

Albert LAVIGNAC, Des Solfeges $2 C$

Albert LAVIGNAC, Des Solfeges $3 \mathrm{~A}$

Fernand FONTAINE, Traite Pratique Du Rythme Mesure (notalan sadece süresi ve ismi ile okumaya yönelik).

Saptanan solfej metotlarındaki alıştırma ve okuma parçaları, amaç doğrultusunda tek tek analiz edilmiş ve veriler ortaya çıkartılmıştır. 


\section{Koro repertuarında seslendirilen parçalar iki bölüme ayrilmaktadır: \\ 1. Eğitim sırasında seslendirilen koro repertuarı: \\ Eğitim sırasında seslendirilen koro repertuarının içinden incelenecek eserlerin saptanması için, Ankara Üniversitesi Devlet Konservatuvarı Opera- Koro Bölümü, Koro Anasanat Dalı koro repertuarı kütüphanesindeki, tüm eserler taranmış ve türlerine göre sınıflandırılmıştır. Sınıflandırılan eserlerden incelenmek üzere seçim yapabilmek için, Koro Anasanat Dalı'nda koro eğitimi veren öğretim elemanlarından görüşler alınmıştır. Seçilmiş koro eserlerinin ana başlıkları aşağıda verilmiştir:}

\section{Ankara Üniversitesi Devlet Konservatuvarı Koro Repertuarı}

Araştırmaya ilişkin seçilen eserler türlerine göre sınıflandırılmıştır:

1) Opera eserleri

2) Sahne eserleri

3) Diğer eserler:
a) Madrigal
b) Koral
c) Missa
d) Spiritüel
e) Motet

4) Ulusal eserler:
a) Şark1
b) Türkü
c) Marş
5) Popüler eserler

2. Eğitim sonrasında seslendirilen koro repertuarı:

Eğitim sonrasında seslendirilen koro repertuarının saptanması için, Kültür Bakanlığı Çoksesli Korosu'ndan destek alınmıştır. Repertuardan, önceden saptanan biçimiyle arşivden elde edilen eserler seçilmiş ve türlerine göre sinıflandırılmıştır. Seçilmiş koro eserlerinin ana başlıkları aşağıda verilmiştir:

\section{Kültür Bakanlığı Çoksesli Korosu Repertuarı}

Araştırmaya ilişkin seçilen eserler türlerine göre sınıflandırılmıştır:

1) Sahne eserleri:
a) Kantat
b) Oratoryo 
c) Requiem

2) Dini eserler

3) Ulusal eserler:

a) Türk besteciler: Şarkılar ve türküler

b) Yabancı besteciler: Şarkılar ve türküler

c) Marşlar

4) Popüler eserler

Şan repertuarında söylenen parçalar iki bölüme ayrılmaktadır:

1) Eğitim sırasında seslendirilen şan repertuarı:

Eğitim sırasında seslendirilen parçaları seçmek için, Ankara Üniversitesi Devlet Konservatuvarı Opera-Koro Bölümü, Koro Anasanat Dalı ve Hacettepe Üniversitesi Devlet Konservatuvarı Şan Sanat Dalı öğretim elemanlarına, sınıflara, bestecilere, eser adlarına, türüne ve ses gruplarına düzenlenmiş bir form verilmiştir. Eserler, genellikle öğrencilerin ölçü açısından karşılaştıkları zorluklar göz önünde tutularak seçilmiştir.

2) Eğitim sırasında ve sonrasında seslendirilen şan repertuarı:

Eğitim sırasında ve sonrasında seslendirilen şan eserlerini seçmek için, öncelikle soprano, mezzo soprano, tenor, bariton ve bas ses grupları için kullanılan albümler saptanmış, bu albümlerden de, ölçü farklılıklarına göre eserler seçilmiş̧ir.

\section{Verilerin Analizi}

Elde edilen verilerin analizi için incelenen ölçüler üç ana gruba ayrılmıştır. Buna göre;

a) Sadece solfej metotlarında bulunan ölçüler,

b) Hem solfej metotlarında hem de repertuarda bulunan ölçüler,

c) Sadece şan ve koro repertuarında bulunan ölçüler.

Tüm ölçüler, birim değerlerine göre yazılmış, ardarda sıralanmış ve bulguların sonunda yorumlar yapılmıştır.

\section{BULGULAR}

$\mathrm{Bu}$ bölümde, elde edilen verilerden hareketle, ulaşılan bulgular ve bunların yorumları yer almaktadır.

Sadece Solfej Metotlarında Bulunan Ölçüler:

a) Üçerli Birim - Birim Noktalı 2'lik: 9/4 ölçü 
Solfej Metotlarında, Şan ve Koro Repertuarında Bulunan Ölçüler:

a) İkişerli Birimler-Birim 2'lik: 2/2 ölçü

3/2 ölçü

4/2 ölçü

Birim 4'lük: 2/4 ölçü

3/4 ölçü

4/4 ölçü

8/8 ölçü

Birim 8'lik: $3 / 8$ ölçü

b) Üçerli Birimiler-Birim Noktalı 2'lik: 6/4 ölçü

Birim Noktalı 4'lük: 6/8 ölçü

$9 / 8$ ölçü

12/8 ölçü

Birim Noktalı 8'lik:12/16 ölçü

c) Ardarda Gelen Ölçü Değişimleri: İki değişik ölçü

Üç değişik ölçü

Dört değişik ölçü

Beş değişik ölçü

Altı değişik ölçü

(Değişen ölçüler, tespit edilen ölçülerden oluşmuştur).

Sadece Şan ve Koro Repertuarında Bulunan Ölçüler:

a) İkişerli Birimler-Birim 2'lik: 5/2 ölçü

$8 / 2$ ölçü

Birim 4'lük: 5/4 ölçü

$7 / 4$ ölçü

Birim 8'lik: 2/8 ölçü

4/8 ölçü

10/8 ölçü

b) Üçerli Birimler-Birim Noktalı 1'lik: 6/2 ölçü

Birim Noktalı 4'lük: 15/8 ölçü

c) Aksak Ölçüler-İki Birimli: $\quad 5 / 8$ ölçü $(2+3 / 3+2)$

$5 / 16$ ölçü $(2+3)$

Üç Bi rimli: $7 / 8$ ölçü $(2+2+3 / 3+2+2)$

$7 / 16$ ölçü $(2+2+3)$

$8 / 8$ ölçü $(2+3+3)$

$8 / 16$ ölçü $(2+3+3)$

Dört Birimli: 9/4 ölçü $(2+2+2+3)$

$9 / 8$ ölçü $(2+2+2+3 / 3+2+2+2)$

$10 / 8$ ölçü $(2+3+2+3 / 3+2+2+3)$

$11 / 16$ ölçü $(2+3+3+3)$ 


\section{TARTIŞMA VE SONUÇLAR}

$\mathrm{Bu}$ araştırmada, şan ve koro sanat dallarında solfej eğitimi kapsamında verilen tartım öğretiminin durumu ele alınmıştır. Bu eğitimin içeriğinin şan ve koro sanat dalları için metodik açıdan uygunluğu araştırılmıştır. Durumun (problemin) araştırılmasında, solfej eğitimi içinde yer aldığı varsayılan tartım (ritm) eğitimi ve öğretiminin boyutunun ölçü açısından eksik olduğu saptanmıştır. Öğretilen ölçüler ile şan ve koro repertuarındaki ölçülerin yeterli derecede örtüşmediği saptanmıştır.

1) Repertuarda olup da, metotlarda yer almayan 19 adet ölçü tespit edilmiştir.

Çizelge 1. Ölçülerin Solfej Metotlarl ve Şan-Koro Repertuarında Yer Alma Durumları

\begin{tabular}{|c|c|c|c|}
\hline No: & Ölçüler & Solfej Metotları & Repertuar \\
\hline 1 & $9 / 4$ & + & - \\
\hline 2 & $2 / 2$ & + & + \\
\hline 3 & $3 / 2$ & + & + \\
\hline 4 & $4 / 2$ & + & + \\
\hline 5 & $2 / 4$ & + & + \\
\hline 6 & $3 / 4$ & + & + \\
\hline 7 & $4 / 4$ & + & + \\
\hline 8 & $8 / 8$ & + & + \\
\hline 9 & $3 / 8$ & + & + \\
\hline 10 & $6 / 4$ & + & + \\
\hline 11 & $6 / 8$ & + & + \\
\hline 12 & $9 / 8$ & + & + \\
\hline 13 & $12 / 8$ & + & + \\
\hline 14 & $12 / 16$ & + & + \\
\hline 15 & Değișen & + & + \\
\hline 16 & $5 / 2$ & - & + \\
\hline 17 & $8 / 2$ & - & + \\
\hline 18 & $5 / 4$ & - & + \\
\hline 19 & $7 / 4$ & - & + \\
\hline 20 & $2 / 8$ & - & + \\
\hline 21 & $4 / 8$ & - & + \\
\hline 22 & $10 / 8$ & - & + \\
\hline 23 & $6 / 2$ & - & + \\
\hline 24 & $15 / 8$ & - & + \\
\hline
\end{tabular}




\begin{tabular}{cccc}
\hline 25 & $5 / 8$ (aksak) & - & + \\
\hline 26 & $5 / 16$ (aksak) & - & + \\
\hline 27 & $7 / 8$ (aksak) & - & + \\
\hline 28 & $7 / 16$ (aksak) & - & + \\
\hline 29 & $8 / 8$ (aksak) & - & + \\
\hline 30 & $8 / 16$ (aksak) & - & + \\
\hline 31 & $9 / 4$ (aksak) & - & + \\
\hline 32 & $9 / 8$ (aksak) & - & + \\
\hline 33 & $10 / 8$ (aksak) & - & + \\
\hline 34 & $11 / 16$ (aksak) & - &
\end{tabular}

2) Solfej metotlarında yer alan ölçülerin büyük bir bölümü repertuarda yer almaktadır.

Çizelge 2. Solfej Metotlarındaki Ölçülerin Durumu

\begin{tabular}{lcc}
\hline Kullanılan Ölçüler & Frekans & (\%) \\
\hline Solfej metotları ve repertuardaki ortak ölçüler & 14 & 93.34 \\
\hline Repertuarda rastlanmayan ölçüler & 1 & 6.66 \\
\hline Solfej metotlarındaki tüm ölçüler & 15 & 100 \\
\hline
\end{tabular}

3) Repertuarda yer alan ölçülerin yarısından fazlası solfej metotlarında yer almamaktadır.

Çizelge 3. Repertuardaki Ölçülerin Durumu

\begin{tabular}{lcc}
\hline Kullanılan Ölçüler & Frekans & (\%) \\
\hline Repertuar ve solfej metotlarındaki ortak ölçüler & 14 & 42.43 \\
\hline Solfej metotlarında rastlanmayan ölçüler & 19 & 57.57 \\
\hline Repertuardaki tüm ölçüler & 33 & 100 \\
\hline
\end{tabular}

Yukarıda da görüldüğü gibi, tüm incelemelerin sonucunda, tartım eğitiminin ölçü açısından büyük ölçüde eksik olduğu belirlenmiştir. 


\section{ÖNERILER}

Halen kullanılmakta olan solfej metotlarının içeriği ile şan ve koro repertuarının içeriği örtüşmediğinden, bu alanda düzenlemeler yapılması gerekmektedir. Bu yapılırken de, araştırmada elde edilen somut veri ve sonuçlardan yararlanmak yerinde olacaktır.

1. Uygulanacak eğitimde, şan ve koro repertuarında yer alan, fakat uygulanmakta olan solfej metotlarında yer almayan 19 ölçüye aşağıda gösterilen siralama önerisine göre yer verilmesi;

a) İkişerli Birimler-Birim 2'lik: 5/2 ölçü

Birim 4'lük: 5/4 ölçü

$7 / 4$ ölçü

Birim 8'lik: 2/8 ölçü

4/8 ölçü

10/8 ölçü

b) Üçerli Birimler-Birim Noktalı 1'lik: 6/2 ölçü

Birim Noktalı 4'lük: 5/8 ölçü

c) Aksak Ölçüler-İki Birimli: 5/8 ölçü $(2+3 / 3+2)$

$5 / 16$ ölçü $(2+3)$

Üç Birimli: 7/8 ölçü $(2+2+3 / 3+2+2)$

$7 / 16$ ölçü $(2+2+3)$

$8 / 8$ ölçü $(2+3+3)$

$8 / 16$ ölçü $(2+3+3)$

Dört Birimli: 9/4 ölçü $(2+2+2+3)$

$9 / 8$ ölçü $(2+2+2+3 / 3+2+2+2)$

$10 / 8$ ölçü $(2+3+2+3 / 3+2+2+3)$

2. Uygulanacak eğitimin içeriğine göre, sonuç ve veriler 1şığında yeni bir solfej eğitimi metodunun yazılması,

3. Yeni bir solfej metodunun yazılamaması durumunda, eksikliği saptanan ölçülerin, uygun başka solfej metotlarıyla desteklenmesi,

4. Başka kaynaklardan yararlanılarak, gerçekleştirilecek eğitim süreçlerinde, birinci öneri maddesindeki sıralamaların dikkate alınması,

5. Araştırmanın sonucuna göre, solfej eğitimi içeriğinin daha kapsamlı ve süresinin daha uzun olacağı anlaşılmış olduğundan, solfej dersi programının buna göre ayrıntılı olarak yeniden yapılandırılması,

6. Solfej öğretim programını tasarlarken, solfej eğitiminin başlangıçtan sonuna kadar ayrıntılı olarak planlanmas1; 
6.a. Öğretilecek ölçüleri sadece tartım metotlarıyla planlayıp öğretmek,

6.b. Öğretilecek ölçüleri solfej ve tartım metotları ile içiçe planlayıp öğretmek.

7. $\mathrm{Bu}$ araştırmada, elde edilen veriler ışı̆̆ında yapılan önerilerin, müziğin diğer dallarında uygulanan solfej eğitimi programlarında da yararlanılması.

\section{KAYNAKLAR}

Balc1, A. (2004). Sosyal bilimlerde araştırma; Yöntem, Teknik ve İlkeler. (4. Baskı). Ankara: Pegem A Yayıncılık.

Bordeausx, M. J. (1985). Nouvelles Leçons Solfege Rytthique. Paris: Gerard Billaudot Editeur.

Carothers Hall, A. (1998). Studyinz Rhythm. (2. Basim). Prentice - Hall, New Jersey: Upper Saddle River 07458

Çelak, İ. (2009). Şan Ve Koro Eğitimi Programlarında Uygulanan Solfej Eğitiminde Tartım Öğretiminin Yeri Ve Bir Model Önerisi. (Doktora Tezi) Ankara Üniversitesi Eğitim Bilimleri Enstitüsü, Ankara.

Dandelot, G. (1935). Etüde du Rythme. (1-5 Metod). Paris: Editions Musicales Alphonse Leduc.

Fontaine, F. (1955). Traite Pratique du Rythme mesure. Paris: Editeurs Henry Lemoine.

Lavignac, A. (1910). Des Solfejes, Volume 1 A. Paris: Copyright, Henry Lemoine.

Lavignac, A. (1910). Des Solfejes, Volume 2 A. Paris: Copyright, Henry Lemoine.

Lavignac, A. (1910). Des Solfejes, Volume 2 C. Paris: Copyright, Henry Lemoine.

Lavignac, A. (1910). Des Solfejes, Volume 3 A. Paris: Copyright, Henry Lemoine.

Say, A. (2005). Müzik Ansiklopedisi. (1. Baskı). Ankara: Müzik Ansiklopedisi Yayınları.

Say, A. (2005). Müzik Sözlüğü. (2. Baskı). Ankara: Müzik Ansiklopedisi Yayınları.

Sun, M. (2005). Solfej 1. (2.Basım). Ankara: SUN Yayınevi

Sun, M. (2005). Solfej 2. (1.Basim). Ankara: SUN Yayınevi

Sun, M. (1997). Temel Müzik Eğitimi 6. Ankara: Doruk Yayınevi

Şteynpress, B. S. Yampolskiy, i. M. (1966). Ansiklopedik Müzik Sözlü̆̆̈̈.

Moskova: Sovyet Ansitlopedisi Yayınları 
Tarman, S. (2006) Müzik Eğitiminin Temelleri. (1. Basım). Ankara: Müzik Eğitimi Yayınları.

\section{Yararlanılan Programlar}

Ankara Üniversitesi Devlet Konservatuvarı Opera - Koro Bölümü, Koro Anasanat Dalı Eğitim Programı

Hacettepe Üniversitesi Ankara Devlet Konservatuvarı Sahne Sanatları Bölümü Opera Anasanat Dalı Lise Devresi Eğitim Programı

Hacettepe Üniversitesi Ankara Devlet Konservatuvarı Sahne Sanatları Bölümü Opera Anasanat Dalı Lisans Devresi Eğitim Programı 
